\title{
Geospatial modelling to estimate the territory at risk of establishment of influenza type A in Mexico - An ecological study
}

\author{
Enrique Ibarra-Zapata, ${ }^{1}$ Darío Gaytán-Hernández, ${ }^{2}$ Verónica Gallegos-García, ${ }^{2}$ \\ Claudia Elena González-Acevedo, ${ }^{2}$ Thuluz Meza-Menchaca, ${ }^{3}$ María Judith Rios-Lugo, ${ }^{2}$ \\ Héctor Hernández-Mendoza ${ }^{4,5}$
}

${ }^{1}$ Center for Research and Postgraduate Studies, Faculty of Agronomy, Autonomous University of San Luis Potosí, San Luis Potosí, S.L.P.; ${ }^{2}$ Faculty of Nursing and Nutrition, Autonomous University of San Luis Potosí, San Luis Potosí, S.L.P.; ${ }^{3}$ Laboratory of Human Genomics, Faculty of Medicine, Veracruzana University, Xalapa, Veracruz; ${ }^{4}$ Desert Zones Research Institute, Autonomous University of San Luis Potosí, San Luis Potosí, S.L.P.; ${ }^{5}$ University of Central Mexico, San Luis Potosí, S.L.P., Mexico

\begin{abstract}
The aim of this study was to estimate the territory at risk of establishment of influenza type A (EOITA) in Mexico, using geospatial models. A spatial database of 1973 outbreaks of influenza worldwide was used to develop risk models accounting for natural (natural threat), anthropic (man-made) and environmental (combination of the above) transmission. Then, a virus establishment risk model; an introduction model of influenza A developed in another study; and the three models mentioned were utilized using multi-criteria spatial evaluation supported by geo-
\end{abstract}

Correspondence: Darío Gaytán-Hernández, Faculty of Nursing and Nutrition, Autonomous University of San Luis Potosí, Av. Niño Artillero \#130, Zona Universitaria, CP 78240, San Luis Potosí, S.L.P., Mexico. Tel.: +52.444.8262300 - ext. 5088.

E-mail: dgaytan@uaslp.mx

Key words: Geographic information systems (GIS); influenza; public health; risk; spatial analysis; Mexico.

Acknowledgements: CONACYT is thanked for a scholarship (EIZ) to pursue the Master's degree.

Contributions: all authors participated in the study: they provided feedback and paid for the analysis, contributed to the presentation and interpretation of all results, integrated constructive criticism in the discussion, and also reviewed various drafts of the manuscript through to its final version. All authors agree with the final version submitted for publication.

Received for publication: 6 February 2021.

Revision received: 13 April 2021.

Accepted for publication: 14 April 2021

CCopyright: the Author(s), 2021

Licensee PAGEPress, Italy

Geospatial Health 2021; 16:956

doi:10.4081/gh.2021.956

This article is distributed under the terms of the Creative Commons Attribution Noncommercial License (CC BY-NC 4.0) which permits any noncommercial use, distribution, and reproduction in any medium, provided the original author(s) and source are credited. graphically weighted regression (GWR), receiver operating characteristic analysis and Moran's $I$. The results show that environmental risk was concentrated along the Gulf and Pacific coasts, the Yucatan Peninsula and southern Baja California. The identified risk for EOITA in Mexico were: $15.6 \%$ and $4.8 \%$, by natural and anthropic risk, respectively, while $18.5 \%$ presented simultaneous environmental, natural and anthropic risk. Overall, $28.1 \%$ of localities in Mexico presented a High/High risk for the establishment of influenza type A (area under the curve $=0.923, \mathrm{P}<0.001$; GWR, $r^{2}=0.840, \mathrm{P}<0.001$; Moran's $\left.I=0.79, \mathrm{P}<0.001\right)$. Hence, these geospatial models were able to robustly estimate those areas susceptible to EOITA, where the results obtained show the relation between the geographical area and the different effects on health. The information obtained should help devising and directing strategies leading to efficient prevention and sound administration of both human and financial resources.

\section{Introduction}

Influenza type A virus infection is caused by a virus of the Orthomyxoviridae family, that represents the greatest risk for global health according to World Health Organization (WHO) criteria; some variants of these viruses, specifically the highly pathogenic ones, now pose a serious threat to public health worldwide (PAHO/WHO, 2018). The pandemic potential of type A virus lies in the constant evolution of variants (Pergolizzi et al., 2020); it is estimated that, globally, annual epidemics cause 3-5 million severe infections and 290,000-650,000 deaths (Vega, 2020). Likewise, the circulation of some subtypes of influenza type A, such as H5, will usually cause serious human disease, and the pandemic subtypes $\mathrm{H} 7 \mathrm{~N} 9$ and $\mathrm{H} 5 \mathrm{~N} 1$ have even presented mortality rates of $27 \%$ and $60 \%$ in SouthEast Asia and the Middle East, respectively (PAHO/WHO, 2018). Nevertheless, it is important to note that H5-type viruses generally infect birds but that they are also responsible for human transmission (Li et al., 2019).

Accordingly, investigations have been pursued in the regions where these types of viruses are considered endemic. In SouthEast Asia, habitat suitability models for the H5N1 virus were developed based on climatic similarity, based on the presence or absence of the serotype (Stevens et al., 2013), and spatial modelling has been carried out for the surveillance of H5N1 in the Middle East by also considering a climatic similarity model 
(Alkhamis et al., 2016). Moreover, other spatial-model studies have been published with regard to spatial-temporal dynamics, propagation and risk of avian influenza (AI) in the Asiatic population (Wang et al., 2010; Zhang et al., 2015; Parque et al., 2017). On the other hand, Gulyaeva et al. (2020) reported a model for AI along the Pacific Rim using geospatial methods. In addition, the use of multiple-criteria decision analysis (MCDA) identified potential high-risk areas by monitoring specific factors (Egli et al., 2019; Younsi et al., 2019; Stenkamp-Strahm et al., 2020). All these contribute to a better understanding of the transmission of influenza viruses that could be estimated in great detail by combining geographic, epidemiological and immunological data. However, it is important to mention that neither did the methodologies consider the natural and anthropic risk aspects of influenza, nor were geostatistical aspects examined to validate the adjustment of the modelling done. Moreover, there is no evidence that natural, anthropic and environmental risk aspects were used in the analysis or the test to validate the estimates made by the model, which implies that the analysis is shallow.

In a study performed at the macro scale to estimate the risk of transmission and propagation of AI (Belkhiria et al., 2016; Global Consortium for H5N8 and Related Influenza Viruses, 2016; Prosser et al., 2016), Ibarra-Zapata et al. (2019) evaluated a scenario of the introduction of influenza type A (IOITA) in Mexico. Regarding the establishment of the AI, a global model for predicting has been proposed, which includes bioclimatic, geographical, and anthropogenic variables in its risk estimation (Herrick et al., 2013). Analysing the spatial association of risk factors and population data is crucial for taking preventive measures and for acting in response to an emerging or re-emerging disease (Belkhiria et al., 2018). Estimation of the risk of EOITA commonly includes the climatic similarity model, receiver operating characteristic (ROC) analysis, geospatial modelling, multi-criteria spatial evaluation and spatial statistics. The climatic similarity model (based on the MaxEnt algorithm) obtains a global character scenario and responds to the conditions that are environmentally similar by pathogenic influenza cases, i.e. it predicts the distribution in environmental conditions and in a determined timeframe (Phillips et al., 2006), Moreover, it is considered the most efficient model currently available for predicting the distribution of species (Elith et al., 2006). Mexico suffered a pandemic outbreak of influenza A (H1N1) in 2009. This was a public health problem whose resolution involved the participation of all social actors, public and private, to implement appropriate mitigation measures aimed at reducing its spread, thereby fostering a sense of security and protection of the general population (Cordova-Villalobos et al., 2017).

During the 2018-2019 season, 187,709 cases of influenza were estimated at the national level in Mexico by the Secretaria de Salud (2020), whose surveillance was carried out following WHO guidelines. Specifically, this strategy relied on sentinel surveillance, which consists of the collection, integration, verification and analysis of epidemiological information from the set of monitoring units, thus enabling the planning of prevention and control interventions in different territories (Cordova-Villalobos et al., 2017). The viruses were classified into highly pathogenic influenza strains - H5N1, H5N2, H5N8, H5N6, H5N3, and H5N9 - some of them considered endemic to their region of origin, but with the potential to mutate via recombination with a low-pathogenicity virus, bringing with it possible effects upon public health (Fernandes-Matano et al., 2019).

This ecological study is based on the analysis of a spatial database of 1973 outbreaks of influenza type A that occurred throughout the world (2014-2016) as confirmed by laboratories of the WHO and the World Organization for Animal Health (OIE), and where PAHO/WHO (2018) and Belkhiria et al. (2018) emphasized that the location of events is a fundamental component. Our aim was to estimate the territory at risk of EOITA in Mexico, by using geo-intelligence, including geostatistical tools and Euclidean distances.

\section{Materials and methods}

The study involved a risk estimate for EOITA concerning the whole territory of Mexico as seen in Figures 1-4 with reference to environmental, natural and anthropic risk characterization.

\section{Environmental risk}

Environmental risk is an essential component in the survival of high and low pathogenicity viruses, one that is mainly associated with temperature and humidity (Olsen et al., 2006). Therefore, an virus establishment model was estimated through the climatic similarity model by incorporating 20 environmental variables from the global BIOCLIM database, each having a spatial resolution of 1 $\mathrm{km}^{2}$ (Belkhiria et al., 2016; Fick \& Hijmans, 2017) (Table 1). Moreover, the model is statistically robust and can be validated with a ROC curve analysis to quantify the area under the curve (AUC) (Herrick et al., 2013). The AUC validates the model performance at estimating those territorial surfaces prone to EOITA.

\section{Natural and anthropic risk characterization}

A geospatial model was developed, by considering the similarities found when comparing different spatial patterns (Harding et al., 2020) that epidemiologically and probabilistically favour the establishment of EOITA. Spatial criteria as random, dispersed or grouped and a High/Low clustering tool have been spatially represented according to the quadrant methodology (Chen, 2020). These values represent spatial autocorrelation of the Getis-Ord $\left(\mathrm{Gi}^{*}\right)$ indices expressed as High/High, Low/Low, High/Low, Low/High and non-significant values, which measure the concentration of values for a study area. In addition, these groupings were defined by the $\mathrm{z}$ score, showing the hotspots and/or coldspots representing the variation of the interval of highly pathogenic influenza according to the risk of establishment obtained (Ord \& Getis, 1995).

The spatial statistical method Gi* measures the degree of spatial association resulting from the concentration of weighted sites and their neighbourhoods within weighted distance radii, classifying the risk in four quadrants (Torres et al., 2017). A reference radial distance of $35 \mathrm{~km}$ was used, following the National Animal Health Device (Secretaría de Agricultura y Desarrollo Rural, 2020). This analysis allows the variables that confer natural and anthropic risk to be associated, by including the bird conservation area as the host's distribution area (Herrick et al., 2013), for characterizing the natural risk of EOITA. This involves accounting for the spatial distribution of the bird conservation areas and they are considered as sites of congregation that enable the viral exchange favouring the emergence of highly pathogenic strains (Bouwstra et al., 2017). By taking such a spatial approach, the epidemiology of avian influenza at the nexus of host, causal agent and environment can be jointly analysed (Stallknecht \& Brown, 2008). The anthrop- 
ic risk was estimated through the coverage of poultry production units (PPU), as represented by the location and capacity of individuals per PPU; small farmers excluded. This made it possible to calculate the density of the PPU in the general neighbourhood according to location. On the other hand, according to Xian et al. (2013), the interaction between humans and poultry favours the evolution and zoonotic transmission of new strains, opening possible avenues to greater human mortality.

\section{Data analysis}

Spatially, each type of risk was represented by a weighting process according to the estimated surface of natural, anthropic, and environmental risk, designated here by hotspots and coldspots. Warm colours (red, orange, yellow) highlight the areas of greater risk compared with cold colours (ranging from blue to green) for areas with a lower risk of establishment. This assessment was done statistically, by applying the method of Gi*. The agglomeration of the risk of virus establishment in space is calculated this way:

$$
\text { SearchRadius }=0.9 * \min \left(S D, \sqrt{\frac{1}{\ln (2)}} * D_{m}\right) * n^{-0.2}
$$

where $S D$ is the standard distance; $D_{m}$ the median distance; $n$ the number of elements; and min minutes.

\section{Integration of environmental, natural and anthropic risks}

A spatial multi-criteria evaluation (SMCE) was applied to estimate the surfaces with characteristics that simultaneously integrate risk of environmental, natural and anthropic virus establishment. For their weighted linear combination, the weight of each factor was first obtained by expert methodology and the standardization of the risk factors achieved by the diffuse membership method (Aguirre et al., 2015). The fuzzy membership defined the respective degree of belonging of the factors. Then, optimal requirements for the establishment of the type A virus were considered on a byte scale ( 0 to 255 ), this being the most recommended approach for spatial aptitude analysis (Tables 1 and 2) (Silva et al., 2017).

Next, the 20 variables were standardized. After this, using the expert method, the weights that each type of risk represents were assigned to estimate the EOITA (Bui et al., 2017). The estimation of loads was expressed based on data characteristics and risk types (Marsh et al., 2018). Moreover, it was assigned the corresponding loads as follows: Introduction risk $=0.25$, Environmental risk $=0.35$; Natural risk $=0.20$, Anthropic risk $=0.20$. Through the weighted linear regression technique, each of the factors was adjusted to generate the risk to public health cartographic model in the estimation of the probabilistic potential of virus establishment, by using this equation (Aguirre et al., 2015):

$$
S=\sum_{i=1}^{n} w_{i} x_{i}
$$

where $S$ is the suitability for establishment; $n$ the number of elements; wi the importance value of the $i$ factor/subfactor; and $x i$ the standardized factor $i$.

The virus establishment potential implicated the analysis of cartographic superposition, With the results obtained, the optimal surfaces for the establishment of this type of virus in Mexico were characterized. It was made according to two essential criteria: the characterization of certain risk factors (environmental, natural, and anthropic) coupled to a consideration of human population density (PD) since it has a dependency relationship with nature (TjonKon-Fat et al., 2016; Sullivan-Wiley \& Gianotti, 2017). On the other hand, anthropic factors constitute a crucial element in the recombination of influenza virus strains and even highly pathogenic viruses such as $\mathrm{H} 5 \mathrm{~N} 1$ can originate from direct or close human interactions with infected, diseased, or dead poultry animals (Bi et al., 2015).

Table 1. Environmental variables from the global BIOCLIM database.

\begin{tabular}{ll}
\hline Variable & Description \\
BI01 & Annual mean temperature \\
BI02 & Mean diurnal range (mean of monthly [max. temp. - min. temp.]) \\
\hline BI03 & Isothermality (BI02/BI07) (100) \\
BI04 & Temperature seasonality (standard deviation 100) \\
\hline BI05 & Max. temperature of warmest month \\
BI06 & Min. temperature of coldest month \\
\hline BI07 & Temperature annual range (BI05-BI06) \\
BI08 & Mean temperature of wettest quarter \\
\hline BI09 & Mean temperature of driest quarter \\
BI010 & Mean temperature of warmest quarter \\
\hline BI011 & Mean temperature of coldest quarter \\
BI012 & Annual precipitation \\
\hline BI013 & Precipitation of wettest month \\
BI014 & Precipitation of driest month \\
\hline BI015 & Precipitation seasonality (coefficient of variation) \\
BI016 & Precipitation of wettest quarter \\
\hline BI017 & Precipitation of driest quarter \\
BI018 & Precipitation of warmest quarter \\
\hline BI019 & Precipitation of coldest quarter \\
BI020 & Elevation (meters above sea level) \\
\hline
\end{tabular}

Table 2. Diffuse membership risk factors of influenza type A.

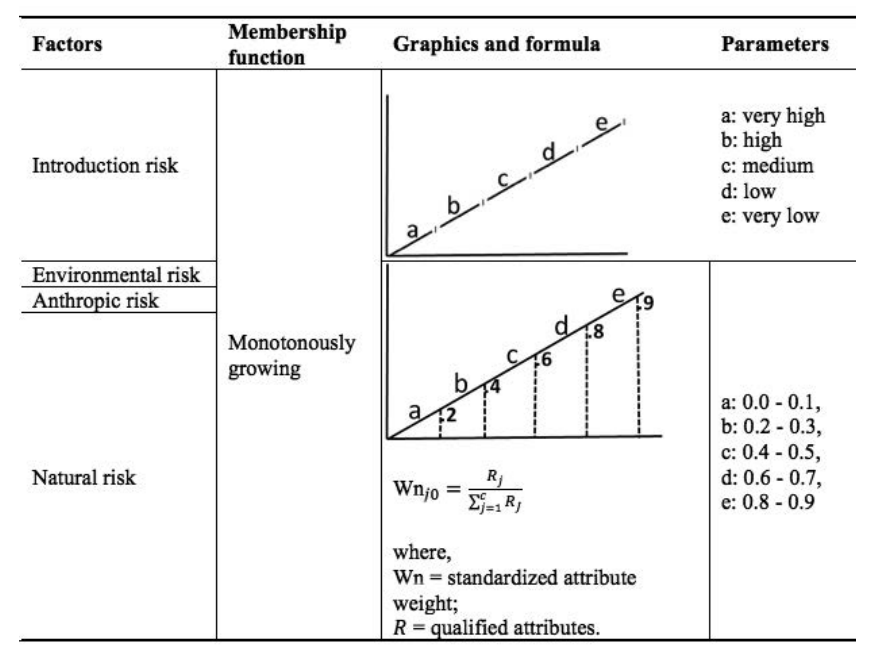




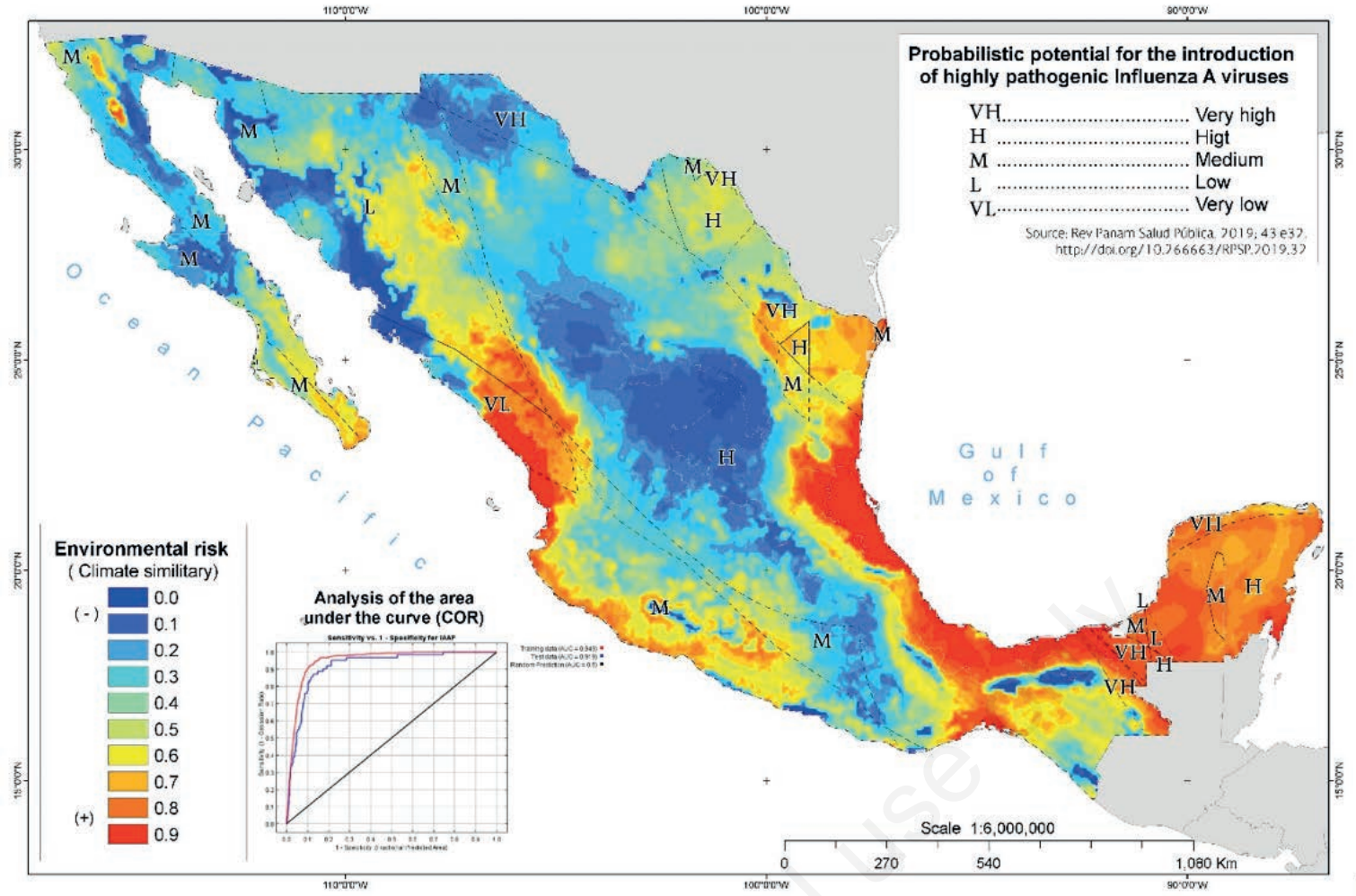

Figure 1. Probabilistic potential modelling for introduction of influenza type A in Mexico.

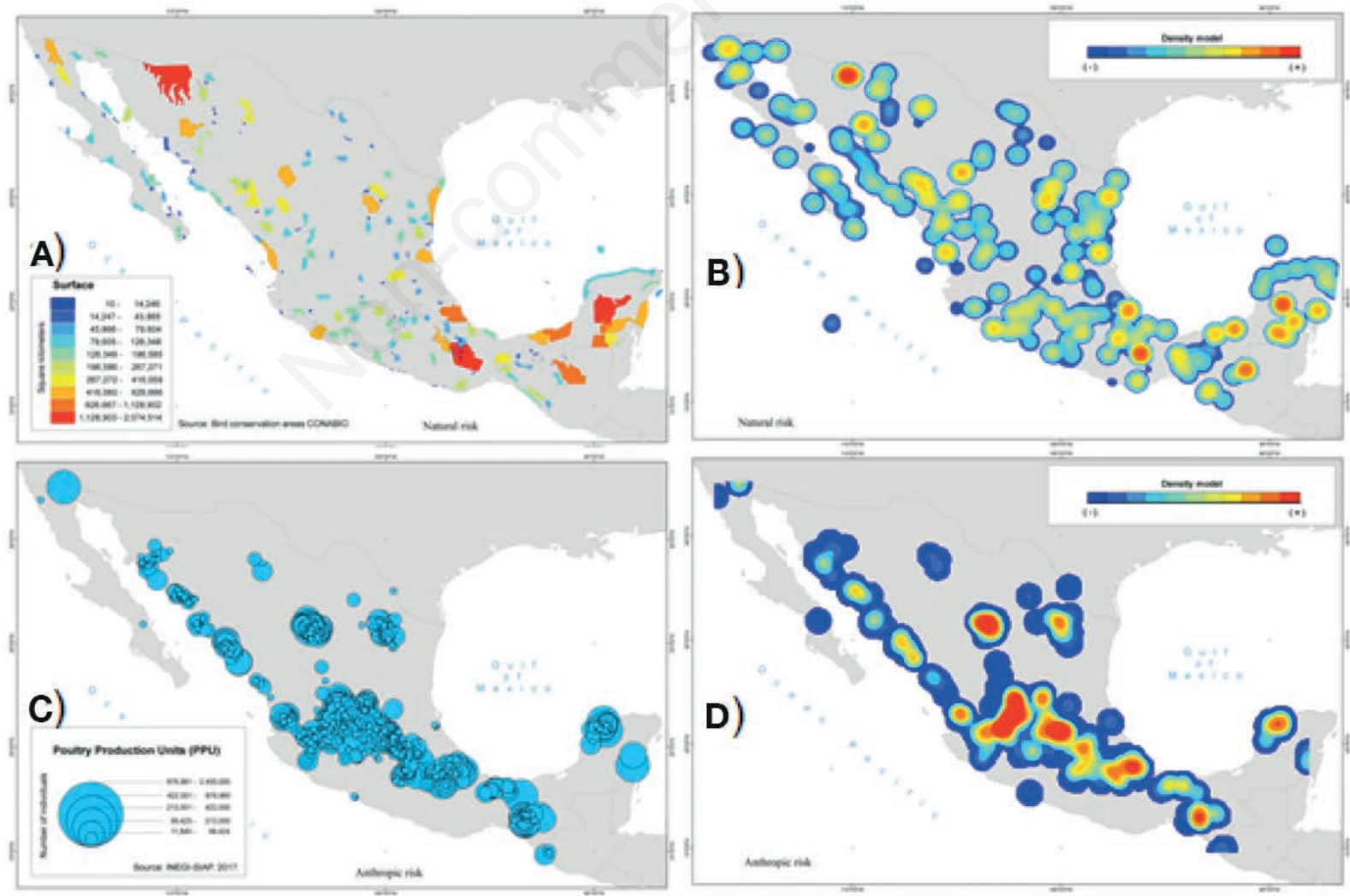

Figure 2. Mexican' map of natural risk and anthropic by the conservation, production, and densi-ties of birds: A) surfaces of natural conservation; B) densities and corridors of natural risk; C) sur-faces of poultry production; and D) densities and corridors of anthropic risk. 


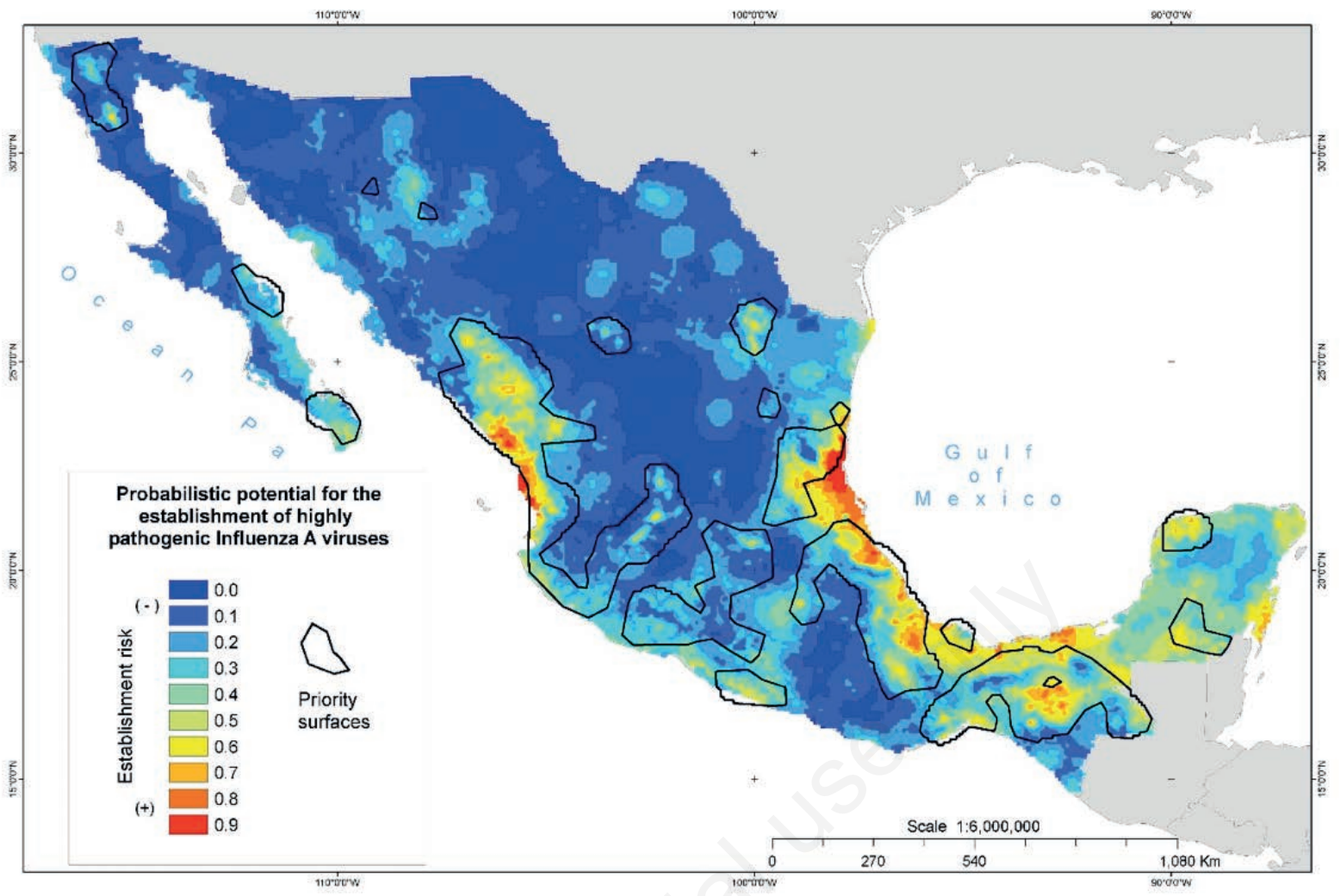

Figure 3. Probabilistic potential modelling of establishment of influenza type A in Mexico.

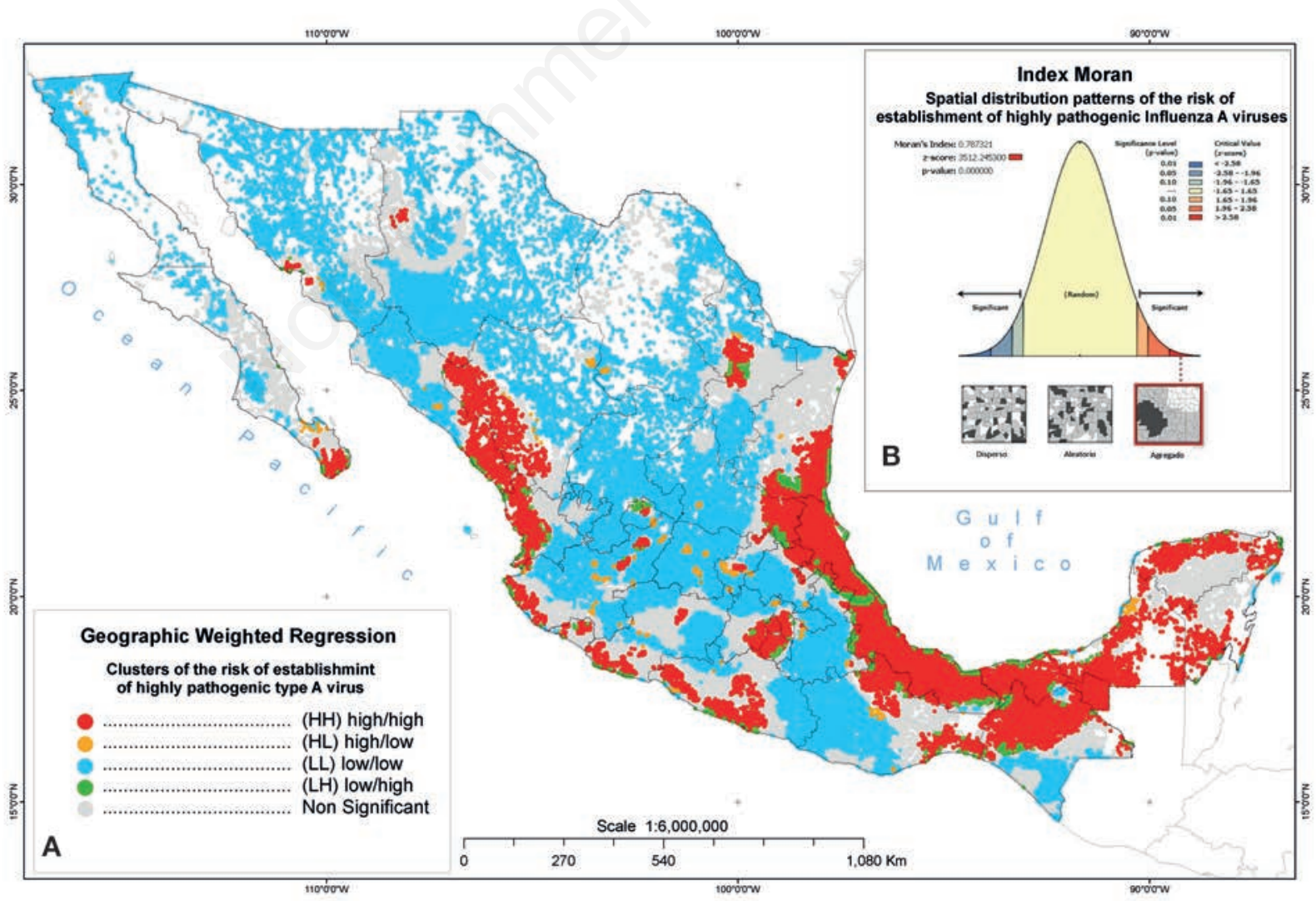

Figure 4. Estimates of the risk of establishment of influenza type A in Mexico. Geographically weighted regression (A) and Moran's I (B). 
Finally, to further strengthen the methodology and offer statistical support, the risk of EOITA was evaluated by geographically weighted regression (GWR), this technique is based on kernel regression (Brundson et al., 1996) and used to examine the spatial variability of a territorial extension. It has the ability to explain the relations between the analysed factors (Mondal et al., 2015). Additionally, the results were then corroborated by the ROC curve, i.e. AUC analysis, and spatial autocorrelation analyses in the form of Moran's $I$. Together, these supplementary analyses made it possible to reliably identify the concentration or dispersion of the values representing the risk of EOITA in Mexico.

\section{Results}

The outcome of the environmental risk model for the EOITA was considered impressive at $\mathrm{AUC}=0.923$. This model was able to spatially represent areas with greater suitability for the establishment of highly pathogenic viruses (warm colours) and areas with lower environmental suitability for these viruses (cold colours) as shown in Figure 1.

The environmental risk of EOITA was defined as a function of the following precipitation variables: the wettest month contributed $22.5 \%$, the average annual temperature $21.3 \%$, seasonality of temperature $11.6 \%$, precipitation of the warmest quarter $6.9 \%$, average temperature of the warmest quarter $5.9 \%$, and precipitation of the coldest quarter $5.5 \%$, with less contributed by the average temperature of the wettest quarter $(3.6 \%)$ and average temperature of the coldest quarter (3.5\%); the other 12 other Bioclim variables contributed jointly the remaining $11.4 \%$. The characterization of the natural risk of virus establishment showed $15.6 \%$ of the Mexican territory to be at risk, amounting to a surface area of $304,500 \mathrm{~km}^{2}$ (Figure 2A). Concerning the anthropic risk of establishment, $4.8 \%$ of the Mexican territory $\left(92,600 \mathrm{~km}^{2}\right)$ it was involved (Figure 2C).

The risk model integrated the areas that simultaneously showed evidence of environmental, natural, and anthropic risks of influenza establishment. These estimations revealed that $0.9 \%$ of the Mexican surface was deemed very high risk for the establishment of EOITA with $5.9 \%$ at high risk, $11.7 \%$ at medium risk and $31 \%$ at low risk, leaving roughly half of the Mexican territory at very low risk of EOITA. Overall, 19 priority clusters carrying virus infection risk were characterized with the largest identified on the Pacific Coast and in the Western part of the country, followed by areas located on the Gulf Coastal Plain, the Isthmus of Tehuantepec, the Yucatan Peninsula, and the Baja California Peninsula, along with some smaller areas found in other parts of the country (Figure 3 ).

The Gi* hot spot analysis showed that $28.7 \%$ of the country was in a High/High risk zone for EOITA, while another 39.5\% was in a Low/Low-risk (LL) zone with statistically significant values. By contrast, $0.38 \%$ of the country had High/Low-risk values and slightly more (1.09\%) featured Low/High-risk values. In $30.9 \%$ of the locations, no significant aggregation of risk was discernible (Figure 4A). The GWR behaved efficiently in that it showed that the model was statistically significant $(\mathrm{P}<0.001)$, with $\mathrm{r}^{2}=0.84$. Hence, the spatial characteristics of the established risk factors, together with population density, explained $84 \%$ of the spatial variation of virus establishment risk across Mexico's territory (Figure $4 \mathrm{~A}$ ). The Moran's $I$ yielded a value of 0.79 , with a $\mathrm{z}=3515$ and $\mathrm{P}<0.001$. This meant the obtained results were statistically signif- icant and demonstrated that the distribution pattern of the establishment risk model was indeed aggregated - with a $<0.01 \%$ probability that the distribution pattern arose from chance - reflecting the positive spatial autocorrelation found in $67.6 \%$ of Mexico's territory (Figure 4B).

\section{Discussion}

The use of geospatial modelling to estimate the virus establishment risk allowed us to characterize the Mexican territory according to epidemiological criteria related to the causative agent of type A influenza. From this method, a key product are the so-called health risk maps, which support decision-making in health policy matters according to the One Health approach proposed by the WHO (Global Consortium for $\mathrm{H} 5 \mathrm{~N} 8$ and Related Influenza Viruses, 2016), especially considering that public health and animal health are linked in the ecosystems in which they coexist (Peiris et al., 2016). The environmental risk model enabled at-risk areas to be adequately classified, and this was validated by ROC analysis, a robust diagnostic where we recorded $\mathrm{AUC}=0.923$, i.e. much higher than its critical cut-off around 0.700 (Herrick et al., 2013). Likewise, the key predictor variables were associated with precipitation, humidity and temperature, together contributing to more than half of the prediction available with the environmental risk model $(62.3 \%)$. This result is similar to previous studies that have demonstrated the effectiveness of this type of analysis for identifying risk scenarios of highly pathogenic viruses in countries and regions, such as Japan (Moriguchi et al., 2013), China (Fang et al., 2013; Artois et al., 2018), the Middle East (Zhang et al., 2012), and the United States (Belkhiria et al., 2016).

We uncovered a natural risk of virus establishment in $15.6 \%$ of the Mexican territory. A possible prevention strategy may be to establish sentinel sites to carry out monitoring activities that support epidemiological surveillance systems in these at-risk areas. The anthropic risk of virus establishment was limited to just $4.8 \%$ of the country's area. Although it is a very low percentage, it should not be neglected because once this type of virus becomes established, nearby regions are at latent risk due to the likelihood the virus will spread. Thus, it is important to maintain PPU facilities in good, hygienic conditions, ideally through proper waste management and disposal.

The spatial interaction between environmental, natural, and anthropic risk factors play a fundamental role in the establishment of highly pathogenic viruses and their possible recombination, as demonstrated by a study carried out in California (Belkhiria et al., 2018). Analysing spatial databases using geographic information systems (GIS), specifically by implementing an SMCE, greatly benefits public health studies due to the possibility of achieving early detection under adverse situations. The present study identified 19 clusters at high-risk for EOITA, areas where all the factors conducive to the establishment of this type of virus converge. This result suggests that epidemiological surveillance systems should be strengthened.

The establishment risk model used in the present study had good geostatistical support, mainly from Moran's I and GWR, which were used to validate the model's estimations. Their robust results provided confidence in the evidence presented for the risk clusters found in Mexico. Finally, it is advisable to strengthen relations between national and international health agencies, which could involve sharing data and institutional information, to 
strengthen the global analysis and thereby estimate influenza outbreak scenarios with greater predictive power.

\section{Conclusions}

The geospatial model developed here to estimate the risk of establishment of type A influenza virus should be useful for epidemiological surveillance in Mexico, and possibly other countries as well, since it incorporates multiple geographic and environmental variables that can lead to optimal conditions for virus establishment in host populations. In tandem, by identifying areas at risk, this modelling can strengthen public health decision-making and facilitate the design of more effective intervention strategies.

\section{References}

Aguirre CA, Valdez JR, Sánchez G, Aragón L, Aguirre AI, 2015. Modelling site selection for tree plantation establishment under different decision scenarios. J Tropical J Trop For Sci 27:298-313.

Alkhamis M, Hijmans R, Al-Enezia A, Martínez B, Perea A, 2016. The use of spatial and spatiotemporal modeling for surveillance of H5N1 highly pathogenic avian influenza in poultry in the Middle East. Avian Dis 60:146-55.

Artois J, Jiang H, Wang X, Qin Y, Pearcy M, Lai S, Shi Y, Zhang J, Peng Z, Zheng J, He Y, Dhingra MS, von Dobschuetz S, Guo F, Martin V, Kalpravidh W, Claes F, Robinson T, Hay SI, Xiao X, Feng L, Gilbert M, Yu H, 2018. Changing geographic patterns and risk factors for avian influenza A (H7N9) infections in humans, China. Emerg Infect Dis 24:87-94.

Belkhiria J, Alkhamis MA, Martínez B, 2016. Application of Species Distribution Modeling for Avian Influenza surveillance in the United States considering the North America Migratory Flyways. Sci Rep 6:33161.

Belkhiria J, Hijmans RJ, Boyce W, Crossley MM, Martinez B, 2018. Identification of high risk areas for avian influenza outbreaks in California using disease distribution models. PLoS One 13:e019082.

Bi Y, Zhang Z, Liu W, Yin Y, Hong J, Li X, Wang H, Wong G, Chen J, Li Y, Ru W, Gao R, Liu D, Liu Y, Zhou B, Gao GF, Shi W, Lei F, 2015. Highly pathogenic avian influenza A (H5N1) virus struck migratory birds in China in 2015. Sci Rep 5:12986.

Bouwstra R, Gonzales JL, de Wit S, Stahl J, Fouchier RA, Elbers $\mathrm{AR}, 2017$. Risk for low pathogenicity avian influenza virus on poultry farms, the Netherlands, 2007-2013. Emerg Infect Dis 23:1510-6.

Brundson C, Fotheringham AS, Charlton ME, 1996. Geographically weighted regression: a method for exploring spatial non-stationarity. Geograph Analysis 28:281-98.

Bui CM, Gardner L, MacIntyre CR, Sarkar S, 2017. Correction: influenza A H5N1 and H7N9 in China: a spatial risk analysis. PLoS One 12:e0176903.

Chen Y, 2020. New framework of Getis-Ord's indexes associating spatial autocorrelation with interaction. PLoS One 15:e0236765.

Cordova-Villalobos JA, Macias AE, Hernandez-Avila M, Dominguez-Cherit G, Lopez-Gatell H, Alpuche-Aranda C, Ponce de León-Rosales S, 2017. The 2009 pandemic in
Mexico: Experience and lessons regarding national preparedness policies for seasonal and epidemic influenza. Gac Med Mex 153:102-110.

Egli A, Saalfrank C, Goldman N, Brunner M, Hollensyein Y, Vogel T, Agustin N, WüthricH D, Seth-Smith MBH, Roth E, Syedbasha M, Mueller FN, Vogt D, Bauer J, Amar-Silva N, Meinel MD, Dubis O, Naegele M, Buser A, Nickel HC, Zeller A, Ritz N, Battegay M, Stadler T, Schneider-Silwa R, 2019. Identification of influenza urban transmission patterns by geographical, epidemiological and whole genome sequencing data: protocol for an observational study. BMJ Open 9:e030913.

Elith J, Graham C, Anderson R, Dudík M, Ferrier, Guisan A, Hijmans R, Huettmann F, Leathwick JR, Lehmann A, Li J, Lohmann L, Loiselle B, Manion G, Moritz C, Nakamura M, Nakazawa Y, Overton JM, Peterson AT, Phillips SJ, Richardson K, Scachetti R, Schapire R, Soberón J, Williams S, Wisz M, Zimmermann N, 2006. Novel methods improve prediction of species distributions from occurrence data. Ecography 29:129-51.

Fang L, Li X, Liu K, Li Y, Yao H, Liang S, Yang Y, Feng Z, Gary G, Cao WC, 2013. Mapping spread and risk of avian influenza A (H7N9) in China. Sci Rep 3:1-8.

Fernandes-Matano L, Monroy-Muñoz IE, de León MB, LealHerrera YA, Palomec-Nava ID, Ruíz-Pacheco JA, EscobedoGuajardo BL, Marín-Budip C, Santacruz-Tinoco CE, González-Ibarra J, González-Bonilla CR, Muñoz-Medina JE, 2019. Analysis of influenza data generated by four epidemiological surveillance laboratories in Mexico, 2010-2016. Epidemiol Infect 147:e183.

Fick SE, Hijmans RJ, 2017. Worldclim 2: New 1-km spatial resolution climate surfaces for global land areas. Int J Clim 37:4302-15.

Global Consortium for H5N8 and Related Influenza Viruses, 2016. Role for migratory wild birds in the global spread of avian influenza H5N8. Science 354:213-7.

Gulyaeva M, Huettmann F, Shestopalov A, Okamatsu M, Matsuno K, Chu D-H, Sakoda Y, Glushchenko A, Milton E, Bortz E, 2020. Data mining and model-predicting a global disease reservoir for low-pathogenic Avian Influenza (AI) in the wider pacific rim using big data sets. Sci Rep 10:16817.

Harding N, Spinney RE, Prokopenko M, 2020. Phase transitions in spatial connectivity during influenza pandemics. Entropy 22:133.

Herrick K, Huettmann F, Lindgren M, 2013. A global model of avian influenza prediction in wild birds: the importance of northern regions. Vet Res 44:42.

Ibarra-Zapata E, Gaytán-Hernández D, Mora Aguilera G, González Castañeda ME, 2019. Escenario de riesgo de introducción de la influenza tipo A en México estimado mediante geointeligencia. Rev Panam Salud Publica 43:e32.

Li Y-T, Linster M, Mendenhall IH, Su YCF, Smit GJD, 2019. Avian influenza viruses in humans: lessons from past outbreaks. Br Med Bull 00:1-15.

Marsh DK, Sculpher M, Caro JJ, Tervonen T, 2018. The use of MCDA in HTA: great potential, but more effort needed. Value Health 21:394-7.

Mondal B, Das DN, Dolui G, 2015. Modeling spatial variation of explanatory factors of urban expansion of Kolkata: a geographically weighted regression approach. Model Earth Syst Environ 1:29. 
Moriguchi S, Onuma M, Goka K, 2013. Potential risk map for avian influenza A virus invading Japan. Divers Distrib 19:78-85.

Olsen B, Munster VJ, Wallensten A, Osterhaus A, Fouchier RA, 2006. Global patterns of influenza A virus in wild birds. Science 312:384-8.

Ord JK, Getis A, 1995. Local spatial autocorrelation statistics: distributional issues and an application. Geograph Analys 27:286-306.

PAHO/WHO (Pan American Health Organization and World Health Organization), 2018. Avian flu. Available from: https://www.paho.org/hq/index.php?option=com_topics\&vie $\mathrm{w}=$ article \&id=344\&Itemid $=40932$ \&lang=es Accessed: 23 June 2020.

Parque J, Jinhwa J, Insung A, 2017. Epidemic simulation of H1N1 influenza virus using GIS in South Korea. pp. 58-60 in International Conference on Information and Communication Technology Convergence (ICTC), Jeju, Korea (South).

Peiris M, Cowling BJ, Wu JT, Feng L, Guan Y, Yu H, Leung GM, 2016. Interventions to reduce zoonotic and pandemic risks from avian influenza in Asia. Infect Dis 16:252-8.

Pergolizzi JV, LeQuang JA, Taylor R, Wollmuth C, Nalamachu M, Varrassi G, Christo P, Breve F, Magnusson P, 2020. Four pandemics: lessons learned, lessons lost. Signa Vitae 1-5.

Phillips S, Anderson R, Sphapire R, 2006. Maximum entropy modeling of species geographic distributions. Ecol Model 190:3-4.

Prosser DJ, Hungerford LL, Erwin RM, Ottinger MA, Takekawa JY, Newman S, Xiao X, Ellis E, 2016. Spatial modeling of wild bird risk factors for highly pathogenic A(H5N1) avian influenza virus transmission. Avian Dis 60:329-36.

Secretaría de Agricultura y Desarrollo Rural, 2020. Manual de procedimientos para la prevención, control y erradicación de la influenza aviar de alta patogenicidad (IAAP). Available from: http://www.zoonosis.unam.mx/contenido/m_academico/archi vos/Manual_Emergencia_control_erradicacion_Influenza_Avi ar_Alta_Patogenicidad.pdf Accessed: February 2020.

Secretaría de Salud México, 2020. Informe semanal de la temporada de influenza estacional 2019-2020 (semana 40 a la 20)/semana 10-2020. Available from: https://www.gob. $\mathrm{mx} / \mathrm{cms} /$ uploads/attachment/file/539259/INFLUENZA_SE10 _2020.pdf Accessed: February 2020.

Silva JJ, Aguirre CA, Miranda L, Sánchez G, Valdéz JR, Pedroza JW, Flores JA, 2017. Locating potential zones for cultivating Stevia rebaudiana in Mexico: weighted linear combination approach. Sugar Tech 2:206-18.

Stallknecht DE, Brown JD, 2008. Ecology of avian influenza in wild birds. Chapter 3. In: Swayne DJ (Ed.), Avian influenza. John Wiley \& Sons, Inc., New York, NY, USA, pp. 43-58.

Stenkamp-Strahm C, Patyk K, McCool-Eye MJ, Fox A, Humphreys J, James A, South D, Magzamen S, 2020. Using geospatial methods to measure the risk of environmental persistence of avian influenza virus in South Carolina. Spat Spatiotemporal Epidemiol 34:100342.

Stevens K, Gilbert M, Pfeiffer D, 2013. Modeling habitat suitability for occurrence of highly pathogenic avian influenza virus $\mathrm{H} 5 \mathrm{~N} 1$ in domestic poultry in Asia: A spatial multi-criteria decision analysis approach. Spat Spatiotemporal Epidemiol 4:1-14.

Sullivan-Wiley KA, Gianotti AGS, 2017. Risk perception in a multi-hazard environment. World Dev 97:138-52.

Tjon-Kon-Fat R, Meerhoff T, Nikisins S, Pires J, Pereyaslov D, Gross D, Brown, WHO European Region Influenza Network, 2016. The potential risks and impact of the start of the 20152016 influenza season in the WHO European Region: a rapid risk assessment. Influenza Other Respir Viruses 10:236-46.

Torres TM, Núñez-Sandoval YC, de la Cruz AJ, 2017. Social representations that adolescents from Guadalajara, México have about human influenza. Actualid Psicol 31:17-30.

Vega R, 2020. El rol de la vacunación contra influenza y su impacto en Cardiología. Rev Colomb Cardiol 27:582-8.

Wang J, Xiong J, Yang K, Peng S, Xu Q, 2010. Use of GIS and agent-based modeling to simulate the spread of influenza. pp. 1-6 in 18th International Conference on Geoinformatics, IEEE.

Xian Q, Yan Q, Chang B, Xi G, Lun C, Fen T, Hong J, Yong H, Pei C, Bing L, Ke X, Chao S, Feng Z, Ming Z, Hua W, 2013. Probable person to person transmission of novel avian influenza A(H7N9) virus in Eastern China. Epidemiological Investigation. BMJ 347:f4752.

Younsi ZF, Hamdadou D, Chakhar S, 2019. A multicriteria spatiotemporal system for influenza epidemic surveillance. In: Nilanjan D. (Ed.), Technological innovations in knowledge management and decision support. IGI Global Publisher, Hershey, Pennsylvania, USA, pp. 27.

Zhang Y, Shen Ma C, Jiang C, Feng C, Shankar N, Yang P, Sun W, Wang Q, 2015. Cluster of human infections with avian influenza A (H7N9) cases: a temporal and spatial analysis. Int J Environ Res Public Health 12:816-28.

Zhang Z, Chen D, Chen Y, Davies T, Jean-Pierre Vaillancourt, JP, Liu W, 2012. Risk signals of an influenza pandemic caused by highly pathogenic avian influenza subtype H5N1: spatio-temporal perspectives. Vet J 192:417-21. 